Research Article

\title{
Dual Equivalent Lateral Force Method for Low-Rise Wooden Horizontal Hybrid Structure with Rigid Core
}

\author{
Di Wu (D), Yoshihiro Yamazaki, and Hiroyasu Sakata \\ Department of Architecture and Building Engineering, Tokyo Institute of Technology, Tokyo 152-8552, Japan \\ Correspondence should be addressed to Di Wu; wu.d.ab@m.titech.ac.jp
}

Received 12 October 2018; Accepted 28 November 2018; Published 17 December 2018

Academic Editor: Shuaishuai Sun

Copyright $\odot 2018$ Di Wu et al. This is an open access article distributed under the Creative Commons Attribution License, which permits unrestricted use, distribution, and reproduction in any medium, provided the original work is properly cited.

\begin{abstract}
Hybrid structure has shown some great features in the earthquake-resistant design. However, due to the different properties between the combined building systems, the distributions of structural mass and stiffness are prevalently irregular in breadth or height, which makes the widely used equivalent lateral force (ELF) method powerless to predict the seismic shear force of such hybrid structure. This study proposed a simple design procedure for determining the concerned seismic shear force of low-rise wooden horizontal hybrid structure in the preliminary linear design. The dual equivalent lateral force (DELF) method is presented that permits the extension of the ELF method by separating the hybrid structure into two independent substructures. It is shown that the proposed DELF method is sufficient to provide a reasonable estimation of the seismic shear force with satisfied accuracy.
\end{abstract}

\section{Introduction}

The concept of hybrid structure has marked one of the useful developments for elevating seismic safety of structural systems since it combines the advantages of different materials and building types. Wooden horizontal hybrid structure, as a novel kind therein, has shown some beneficial features in improving the seismic performance compared to the traditional lightweight wood structure. The representative type of the wooden horizontal hybrid structure is shown in Figure 1. The wooden part is a multistory lightweight wood frame with a lateral shear resistance member. And it is horizontally connected to the relative rigid core part, which is built with steel frame, concrete frame, or concrete shear wall system. In a symmetric design, the wooden parts are separated by the core parts in the length of the building. The earthquake input direction studied in this study is vertical to the length of the building since the wooden part is a complex multi-degreeof-freedom system in that direction. During the earthquake, the seismic force derived from the wooden part is transferred in two ways: one way through the lateral shear member (wood shear wall or moment-resisting frame) to the ground and the other way through the diaphragm to the core part. In addition, the gravities of the two parts are sustained by their respective vertical components. The irregularity of horizontal stiffness usually causes torsion in seismic scenario for traditional building type (Figure 1(c)). However in this wooden horizontal hybrid type, the wooden flexible diaphragm suppresses the torsion vibration of the whole building, resulting in the major shear deformation of the diaphragm itself (Figure 1(d)). Also, the preferred symmetric design provides further suppression on the torsion vibration. Therefore, the wooden part could be simplified into a $2 \mathrm{D}$ frame in which only the shear deformation is concerned (Figure 1(b)).

The characteristics of structure with flexible diaphragm and rigid core have been studied by several researchers. Kim and White [1] investigated the results of shaking table tests on a half-scale one-story reinforced masonry building with a flexible diaphragm, and based on the test, a simplified multiple-degree-of-freedom approach was proposed and corresponding model calibration process was performed to provide accurate prediction of the dynamic response. Lee et al. [2] found that, in structures with flexible diaphragm as the diaphragm became more flexible, the contribution of higher mode tended to be increasing, and a mode-based method was proposed to estimate the 


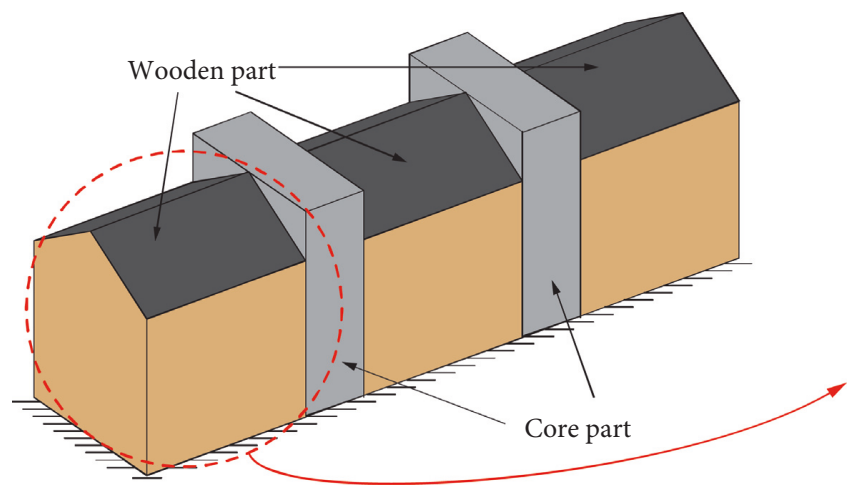

(a)

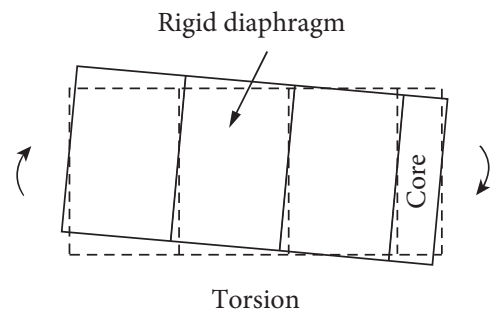

(c)

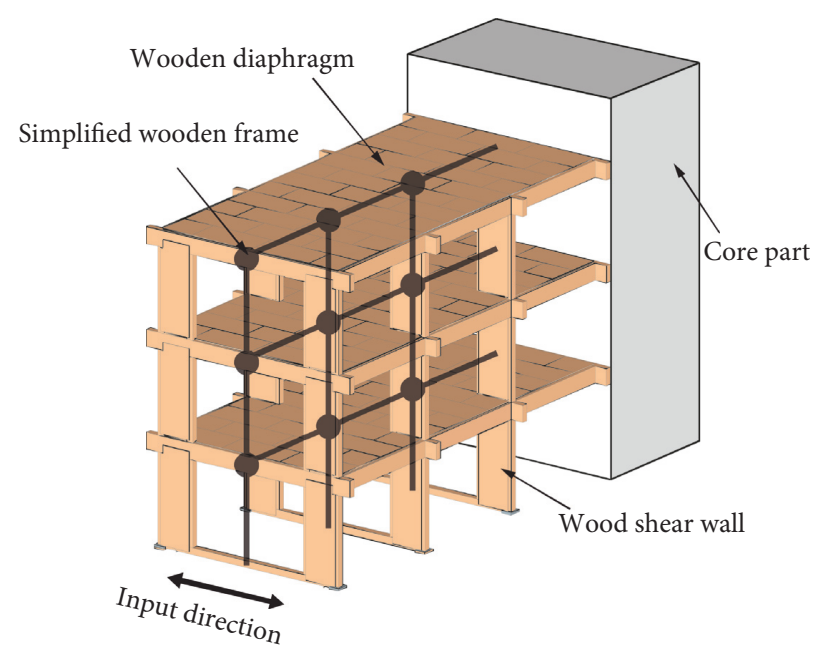

(b)

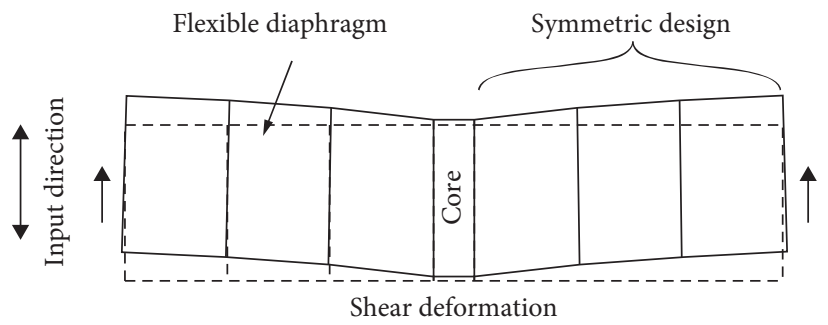

(d)

FIGURE 1: Typical type of wooden horizontal hybrid structure. (a) General layout. (b) One kind of detailed design of the wooden part and the possible simplified frame. Relative deformation mechanism (c) building with rigid diaphragm and (d) building with flexible diaphragm and symmetric design.

interstory drift of low-rise structures with a flexible diaphragm. Humar and Popovski [3] presented the linear and nonlinear seismic responses of large-scale single-story building with flexible diaphragms. Koliou et al. [4, 5] studied the collapse performance of the rigid wall-flexible diaphragm system and proposed a seismic design approach to account for flexible roof diaphragm response by distributing yielding in the roof diaphragm as the predominant inelastic response under extreme ground shaking.

For a more specific category, the wood-based horizontal hybrid structure, researches have also been carried out experimentally and theoretically. Yamazaki and Sakata [6] used a two-dimensional continuous body to simulate the vibration of the hybrid structure and proposed practical formulae to evaluate the amplitude and distribution of the seismic force. Goertz et al. [7] proposed an energy-based method in designing a multistory hybrid building consisting of a timer-steel core wall system. Isoda et al. $[8,9]$ conducted a full-scale shaking table test on a woodreinforced concrete system. The test found that the connection between the wooden part and the core part was crucial since it governed the deformation and energy dissipation of the wooden part. Wu et al. [10] reported the shaking table test results of three 1/3-scale specimens with different shear wall configurations and diaphragm stiffnesses. Results showed that the seismic force distribution between the wooden part and the core part was significant for the design of horizontal hybrid structure.

Notwithstanding these findings, a simple procedure is still required to estimate the seismic force for the horizontal hybrid structure, especially in the preliminary linear design stage. In earthquake engineering practice, an equivalent lateral force (ELF) method has been widely used for the linear seismic analysis. Although the ELF method has strict prerequisites and the results are approximate, it has been absorbed into the building codes of many counties [11-14] on account of the convenience during the linear seismic design. However, due to the inherent lateral irregularity in both mass and stiffness, a wooden horizontal hybrid structure is theoretically difficult to be analyzed by the ELF method. To estimate the seismic force of the wooden horizontal hybrid structure, a new approximation is developed in this study by using the theory of the ELF method and the proposed dual equivalent lateral force (DELF) method is tested by the case study of the shaking table test conducted in the companion paper [10]. It is shown that the DELF method is sufficient to provide a reasonable estimation of the seismic force for the linear seismic design.

\section{Dual Equivalent Lateral Force Method}

The DELF method is difficult to be conducted and testified on a real horizontal hybrid building at this stage, considering 
the absence of engineering practice and seismic record. As an alternative approach, the shaking table test on the horizontal hybrid structure is an ideal analysis object with its controllable condition and detailed record. Therefore, one of the test specimens is chosen from the conducted shaking table test in the companion paper [10] to illustrate the whole procedure of the DELF method. The chosen test specimen is a typical horizontal hybrid structure. The wooden part is a 3story, 3-bay wood frame with two shear panels at each frame of all the 3 stories (Figure 2). The story stiffness and seismic mass of the wooden part are approximately uniform along the height and the length. The core part is a rigid steel frame which has high lateral stiffness along the input direction. In the test specimen, the stiffnesses of the wood shear wall and the wood diaphragm were quite close, and the stiffness of the core part was nearly 23 times greater than the wooden part which is applicable for the DELF method. A more detailed description of the test and the specimen is given in the companion paper [10].

For the DELF method, firstly, the hybrid structure should be simplified as a $2 \mathrm{D}$ frame which is perpendicular to the concerned input direction (Figure 3(a)). When the hybrid structure is subjected to the seismic scenario in the concerned direction, the wooden part vibrates as a two-edgeconstrained plate [6]. The main idea of the DELF method is to separate the complex vibration mechanism of the wooden part into two distinct components: one is the vibration of an ordinary independent wood frame, namely, Substructure A (Figure 3(b)); the other one is the vibration of a horizontally oblique wooden frame, namely, Substructure B (Figure 3(c)). The separation is arbitrary and has no distinct theoretical argument; however, the basic structural implication exists: restrains of the wooden part are released, respectively, and the responses of the corresponding substructures are combined to get the responses of the original fully restrained wooden part. In Substructure A, the restraint of the core part is released; in Substructure B, the restraint of the ground is released and the rigid core part could be considered as the ground, while the diaphragm is regarded as the shear wall of the frame. Both substructures are then simplified to a simple lumped mass system and evaluated by the ELF method, respectively (Figures 3(d) and 3(e)). Naturally, the assumptions of the ELF method restrain the scope of this study. Different building codes propose specific limitations of using the ELF method, but most general limitations are structure regularity and its height or period. Therefore, the hybrid structure studied here should be a low-rise building in both height and length, and also the wooden part could be divided into regular story levels with uniform or approximately uniform mass and stiffness along the vertical and horizontal orientation. It is worth noting that the core part in Substructure B is assumed to act as the ground which could provide equal acceleration along the height; however, since the core part is not perfectly rigid, the actual acceleration is always higher on the upper story which makes the DELF method inevitably underestimate the seismic demands of the upper story. In fact, research indicated that the formal frequency ratio between the core part and the wooden part should be higher than 3 to make sure that the fundamental

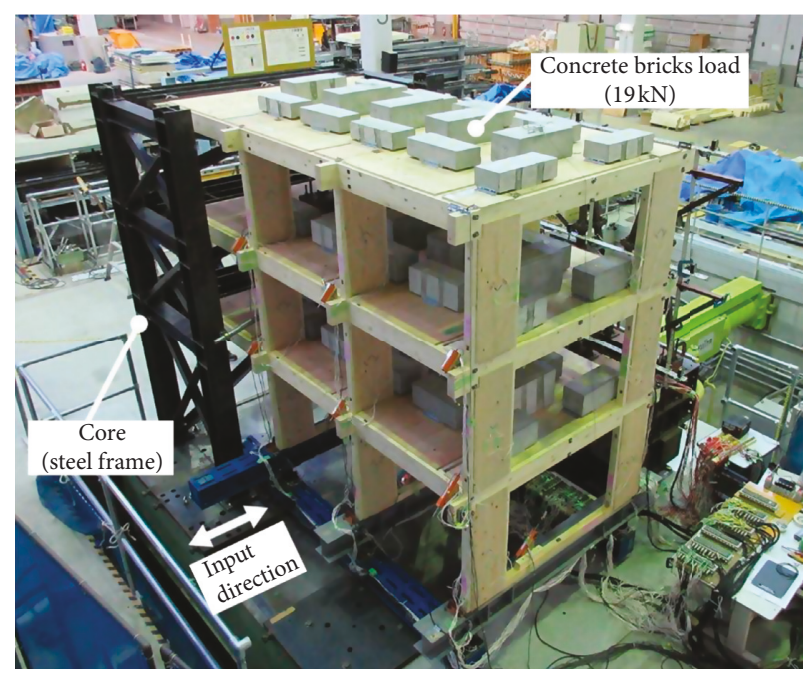

Figure 2: Chosen shaking table test specimen to conduct the DELF method.

mode vibration of the wooden part was not notably affected by the vibration of the core part [15].

There exists another concern about the connection between the wooden part and the core part. The experiment indicated that the connection may suffer from severe damage when the hybrid structure is subjected to major earthquakes [9]. However, for the ELF and DELF methods, the involved design stage is the minor earthquake during which the whole hybrid structure is supposed to be linear including the connection. Regardless of the use of a damper or a seismic isolation device at the connection part, the shear stiffness of the connection should be much higher than that of the diaphragm. In that condition, the assumption about approximately perfect fixity between the wooden part and the core part is reasonable, and the Substructure B could be evaluated by the ELF method. After the ELF analyses of Substructure A and Substructure B are finished, the seismic force of each story is distributed to each lumped node by the weight of the node mass (Figures 3(f) and 3(g)). Then the seismic forces of these two substructures are combined by the stiffness of the relative vertical force transfer element: the wood shear wall in Substructure A and the diaphragm in Substructure B (Figure 3(h)). The weighted geometric mean is used here, and the weight factor represents the period difference between the substructures and the original wooden part. Higher stiffness of vertical force transfer element means closer period with the original wooden part and the higher participation in the fundamental vibration.

The DELF method shown in Figure 3 is summarized in the following procedure:

Step 1. The wooden horizontal structure is separated into two substructures in which the constraint of the core part and the ground is released, respectively (Figures $3(\mathrm{a})-3(\mathrm{c})$ ).

Step 2. Regardless of the gravity force, the substructures could be considered as structures with uniformly distributed mass and stiffness, which are applicable to the ELF method. 


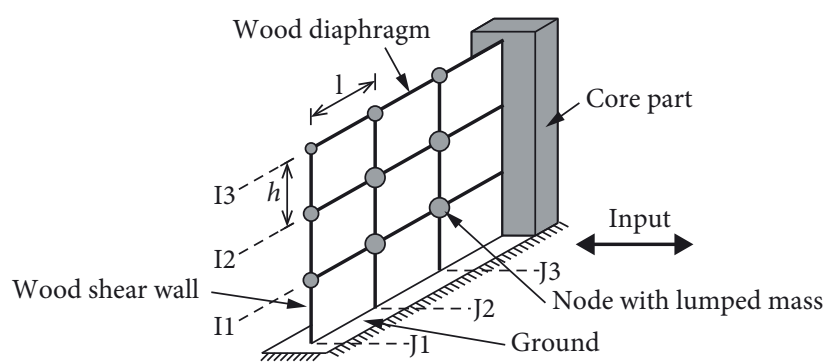

(a)

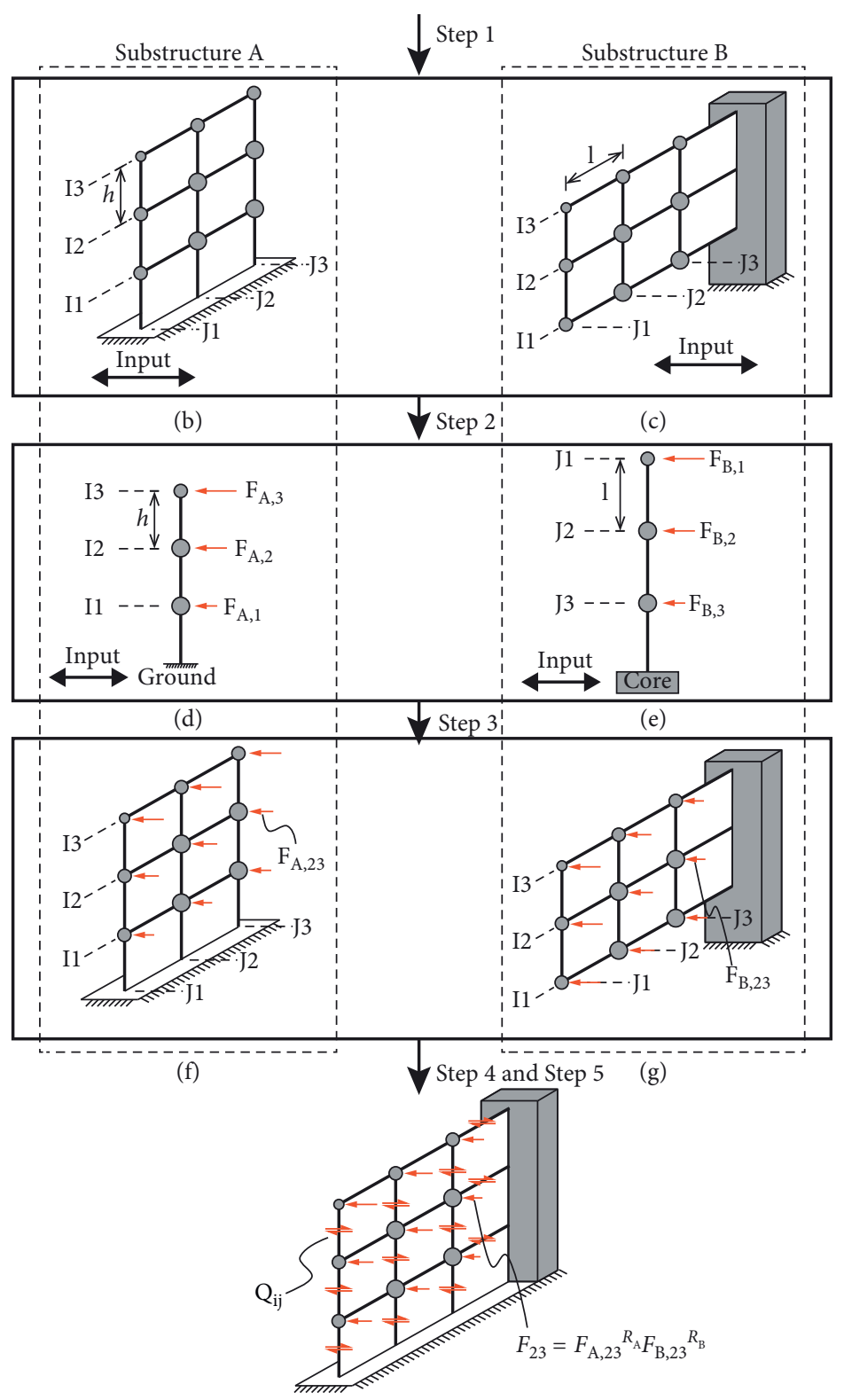

(h)

FIgURE 3: Flowchart of the DELF method.

For Substructure A, the standard ELF analysis [11] is carried out by equations (1)-(3) (Figure 3(d)):

$$
\begin{gathered}
F_{\mathrm{A}, i}=C_{\mathrm{A}, i} V, \\
V=C_{\mathrm{s}} W,
\end{gathered}
$$

$$
C_{\mathrm{A}, i}=\frac{w_{i} h_{i}}{\sum_{i=1}^{n} w_{i} h_{i}}
$$

where $F_{\mathrm{A}, i}=$ lateral seismic force of $i$ story, $W=$ total effective seismic weight, $C_{\mathrm{A}, i}=$ vertical distribution factor of $i$ 
story, $w_{i}=$ seismic weight of $i$ story, $V=$ total design base shear, $h_{i}=$ height of $i$ story, $C_{\mathrm{s}}=$ seismic response coefficient of hybrid structure, and $n=$ number of stories.

It should be pointed out that when defining $C_{\mathrm{s}}$, the period used should be one of the original hybrid structures rather than one of the Substructures A or B.

Step 3. For Substructure A, once the ELF analysis of each substructure is finished, the seismic force of each story is distributed to the respective nodes by the lumped seismic mass by equation (4) (Figure 3(f)):

$$
F_{\mathrm{A}, i j}=\frac{w_{i j}}{w_{i}} F_{\mathrm{A}, i},
$$

where $F_{\mathrm{A}, i j}=$ lateral seismic force of the node at $i$ story and $j$ frame in Substructure A and $w_{i j}=$ seismic weight of the node at $i$ story and $j$ frame.

Repeat Step 2 and Step 3 for Substructure B to get the seismic force $F_{\mathrm{B}, i j}$ at each node (Figures $3(\mathrm{e})$ and $3(\mathrm{~g})$ ).

Step 4. The seismic forces at the same node of Substructures $\mathrm{A}$ and $\mathrm{B}$ are combined using the weighted geometric mean by equations (5)-(7) (Figure $3(\mathrm{~h})$ ):

$$
\begin{aligned}
& F_{i j}=F_{\mathrm{A}, i j}^{R_{\mathrm{A}}} F_{\mathrm{B}, i j}^{R_{\mathrm{B}}}, \\
& R_{\mathrm{A}}=\frac{\sqrt{K_{\mathrm{s}}}}{\sqrt{K_{\mathrm{s}}}+\sqrt{K_{\mathrm{d}}}}, \\
& R_{\mathrm{B}}=\frac{\sqrt{K_{\mathrm{d}}}}{\sqrt{K_{\mathrm{s}}}+\sqrt{K_{\mathrm{d}}}},
\end{aligned}
$$

where $F_{i j}=$ combined seismic force of the node at $i$ story and $j$ frame in the original structure, $R_{\mathrm{A} / \mathrm{B}}=$ the weighting factor of Substructure A/B, $K_{\mathrm{s}}=$ the stiffness of the wood shear wall, and $K_{\mathrm{d}}=$ the stiffness of the diaphragm.

Step 5. Apply the combined force $F_{i j}$ on the original hybrid structure statically to get the estimated seismic shear force $Q_{i j}$ of the shear wall and diaphragm in the wooden part (Figure 3(h)).

Once the DELF analysis of the wooden part is completed, the core part could be analyzed independently by using the standard ELF method. Accordingly, the shear force of the core part is the combination of the ELF method's result and the shear force transferred from the wooden part through the diaphragm which could be obtained from Step 5 .

\section{Case Study}

The case study is performed based on the proposed DELF method. Two structures are studied: Case 1 is the chosen test specimen shown in Figure 2; Case 2 is a hypothetical structure which has the same configuration with Case 1 except the diaphragm stiffness, which is 10 times the one of Case 1. For the horizontal hybrid structure, the potential design of the diaphragm may include wooden panel, steel deck, or concrete panel. Therefore, the stiffness of the diaphragm may change in a wide range due to different designs. The given difference between the two cases is to investigate the stability of the DELF method under various diaphragm designs.

In the shaking table test [10], the specimen was subjected to the time-scaled BCJ-L2 wave [16] with increasing peak ground acceleration (PGA) from $0.1 \mathrm{~g}$ to $0.8 \mathrm{~g}$. To compare with the test results, the same time-scaled BCJ-L2 wave is chosen as the design ground motion in the DELF method. The spectral acceleration of the BCJ-L2 wave is shown in Figure 4. The PGA of the BCJ-L2 wave is set to $0.1 \mathrm{~g}$, at which level the hybrid structure is verified to be linear and suitable for the DELF method. To avoid the tedious calculation procedure, the seismic response coefficient $C_{s}$ in equation (2) is arbitrarily set to the spectral acceleration of the design ground motion at the fundamental period of the test specimen, instead of a comprehensive consideration of building importance, site class, seismic hazard, etc. Fundamental periods of Cases 1 and 2 are depicted in Figure 4. The relative spectral accelerations are used as $C_{s}$ in the DELF method. Moreover, the total effective seismic weight $W$ was set to $85 \%$ of the total weight of the building considering the horizontal hybrid structure is a multiple-degree-of-freedom system [14]. The simplification of $C_{\mathrm{s}}$ and reduction of $W$ seems to be reasonable in terms of the expected match in the following results. Meanwhile, modal response spectrum (MRS) approach [17] is also performed using the eigenvalue derived from a simplified linear model as shown in Figure 5. The shear wall and diaphragm of the wooden part are simulated with linear shear spring, and the stiffness of the spring is derived from the measured initial stiffness of the shaking table test specimen [10]. The value of the lumped mass is also calculated directly from the test specimen. Since the specimen is a 3 story low-rise building, only the fundamental mode of vibration is used in the MRS. Meanwhile, the stiffness of the core part in the linear model is set to 1000 times higher than the shear wall to get an ideal rigid core part in both Case 1 and Case 2. Table 1 demonstrates the detailed parameter used in the DELF and MRS.

The results of the DELF and MRS analyses and shaking table test for Case 1 are demonstrated in Figure 6(a). The listed values refer to the peak shear force of the shear walls and the diaphragms connected to the core part. The error between the test results and the prediction of the MRS and DELF methods is also depicted in Figure 6(a). The error is defined by the following equation:

$$
\text { error }=\frac{\text { MRS or DELF }- \text { test }}{\text { test }} \times 100 \% \text {. }
$$

The accordance of the peak shear forces is satisfactory for both shear wall and diaphragm. The shear force of the wood shear wall gives a margin of error with nearly $10 \%$ between the DELF and the test in the $1^{\text {st }}$ and $2^{\text {nd }}$ stories. The agreement of the diaphragm is also acceptable especially in the concerned soft segment. The soft segment refers to the shear wall of the $1^{\text {st }}$ story and the diaphragm connected to the core part where the deformations of those shear components are much higher than other parts of the hybrid structure [10]. Meanwhile, the error of the total wood base shear is $1 \%$ which is astonishingly precise for the preliminary 


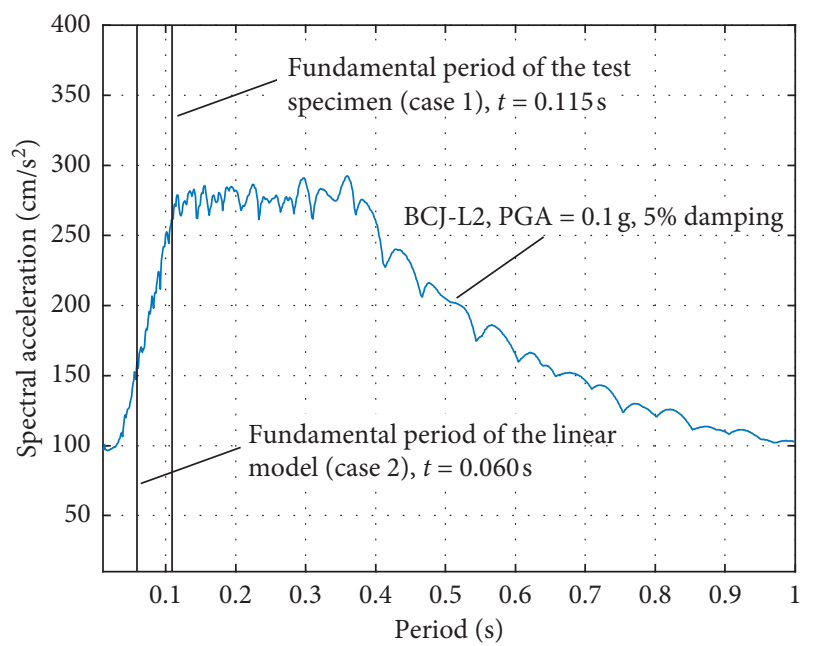

FIgure 4: Spectral acceleration of the scaled BCJ-L2 wave and the fundamental period of Case 1 and Case 2.

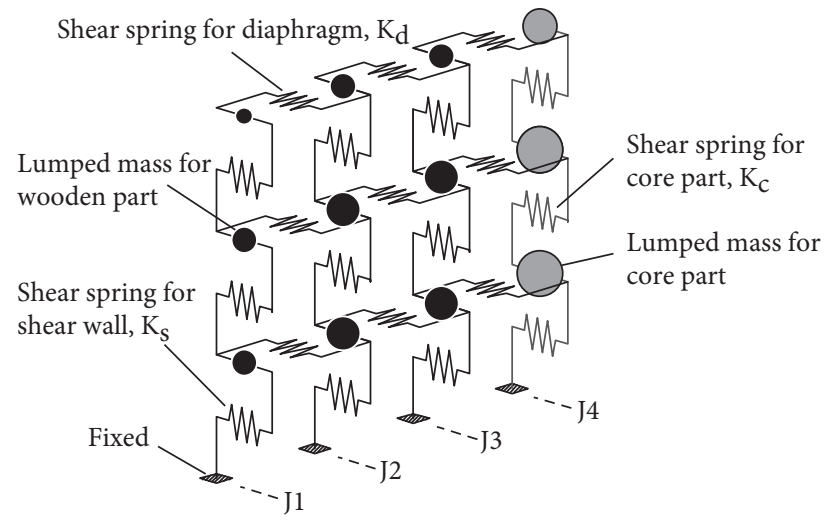

FIGURE 5: Linear model to calculate the fundamental mode of vibration for the MRS method.

TABLE 1: Structural weight $(N)$ and shear stiffness $(\mathrm{N} / \mathrm{mm})$ used in DELF and MRS.

\begin{tabular}{lccccccccc}
\hline Value $(N, N / \mathrm{mm})$ & $w_{12} w_{13} w_{22} w_{23}$ & $w_{11} w_{21}$ & $w_{32} w_{33}$ & $w_{31}$ & $w_{41} w_{42}$ & $w_{43}$ & $K_{\mathrm{s}}$ & $K_{\mathrm{d}}$ & $K_{\mathrm{c}}$ \\
\hline Case 1 & 3283 & 1754 & 2146 & 1117 & 6693 & 5282 & 1250 & 1313 & $1250 \mathrm{e} 3$ \\
Case 2 & 3283 & 1754 & 2146 & 1117 & 6693 & 5282 & 1250 & 12500 & $1250 \mathrm{e} 3$ \\
\hline
\end{tabular}

design. The main discrepancy between the DELF analysis and the test is focused on the $3^{\text {rd }}$ story where the error is increasing from $X 1$ to $X 3$. This error is derived from the inherent limitation of the ELF method in which the response of the upper story could be underestimated to some extent, depending on the configuration of the building. Some building codes attempt to amend that underestimation by introducing an additional seismic force at the top of the building $[13,14]$. While in DELF method, the underestimation occurred in the area which is of little importance compared with the soft segment; therefore, no additional force was involved here. It is worth noting that although the MRS method tended to somehow overestimate the seismic shear in the $1^{\text {st }}$ and $2^{\text {nd }}$ stories, the results of DELF and MRS methods are of comparable quality through all the stories. It adds weight to the idea that the combination of the vibration of the two substructures is equivalent to the fundamental mode of the original wooden part, which verifies the rationality of the DELF method.

In Case 2, only the results of DELF and MRS methods are presented since there is no corresponding test (Figure 6(b)). The disparity between DELF and MRS methods increased compared with Case 1 , especially in the $3^{\text {rd }}$ story. The increase of the diaphragm stiffness may change the vibration shape of the fundamental mode which could not be fully compensated by the weighting factor in the DELF method. Nevertheless, in the concerned soft segment, the results of the DELF and MRS methods are close and acceptable at the level of construction engineering. In general, the DELF method provides a reasonable prediction of the seismic force with the same accuracy as that of the MRS method but lesser computing work for the wooden hybrid structure. 


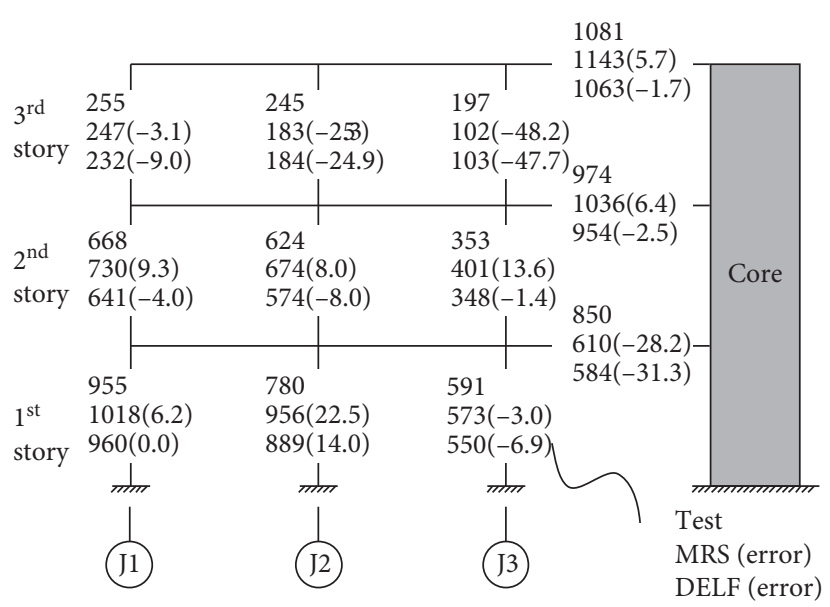

(a)

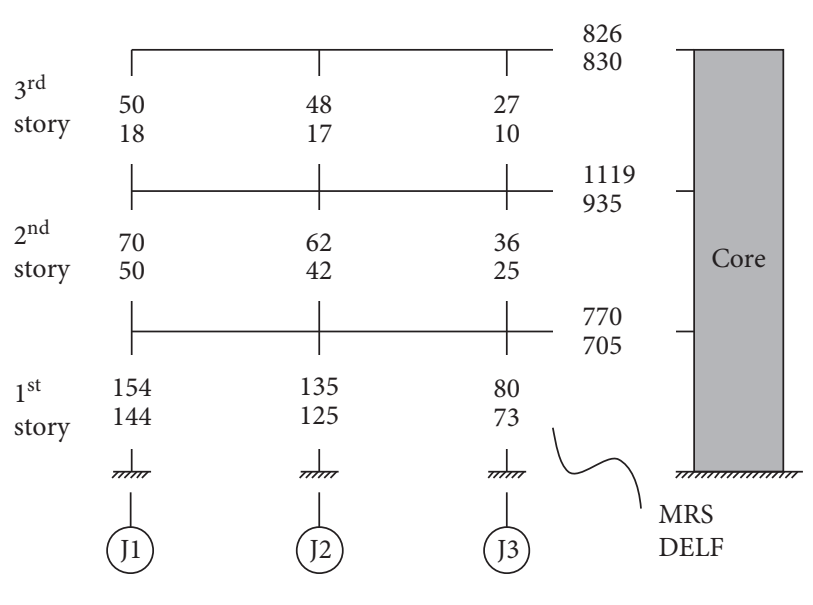

(b)

FIGURE 6: Peak shear force of the shear wall and diaphragm by DELF, MRS, and shaking table test results, PGA = 0.1 g, unit: N. (a) Case 1: $K_{\mathrm{s}} \approx K_{\mathrm{d}}$. (b) Case $2: K_{\mathrm{s}}=10 K_{\mathrm{d}}$.

\section{Conclusion}

A simplified method has been proposed for the estimation of the seismic shear force for the preliminary linear design of low-rise wooden horizontal hybrid structure. This method requires the knowledge and prerequisites of the equivalent lateral force method and therefore has the succeeded advantages and limitations. The proposed dual equivalent lateral force method could be sufficient to predict the approximate seismic shear force if the wooden part has a relatively uniform distribution of stiffness and mass. The calculation procedure is also straightforward and could be conducted manually. However, the DELF method has done a poor job predicting the shear force in the upper story. The seismic shear of the shear wall is underestimated by up to $55 \%$ in the top story. Accordingly, additional roof seismic load may be necessary for the DELF method. Besides, the increase of stiffness difference between the shear wall and the diaphragm in the wooden part could affect the accuracy of the DELF method.

There should also be pointed out that, in the case study, the seismic response coefficient is set to the spectral acceleration arbitrarily which eventually gives a reasonable result. While in the engineering practice, the seismic response coefficient is of great concern since it is related to various factors and could have great influence on the ELF and DELF analysis results. Meanwhile, further study is required for the applicability of the DELF method associated with various configurations, such as the number of stories and the stiffness ratio between the shear wall and diaphragm.

\section{Data Availability}

The data used to support the findings of this study are available from the corresponding author upon request.

\section{Conflicts of Interest}

The authors declare that there are no conflicts of interest regarding the publication of this paper.

\section{References}

[1] S.-C. Kim and D. W. White, "Nonlinear analysis of a one-story low-rise masonry building with a flexible diaphragm subjected to seismic excitation," Engineering Structures, vol. 26, no. 14, pp. 2053-2067, 2004.

[2] H. J. Lee, D. Kuchma, and M. A. Aschheim, "Strength-based design of flexible diaphragms in low-rise structures subjected to earthquake loading," Engineering Structures, vol. 29, no. 7, pp. 1277-1295, 2007.

[3] J. Humar and M. Popovski, "Seismic response of single-storey buildings with flexible diaphragms," Canadian Journal of Civil Engineering, vol. 40, no. 9, pp. 875-886, 2013.

[4] M. Koliou, A. Filiatrault, D. J. Kelly, and J. Lawson, "Distributed yielding concept for improved seismic collapse performance of rigid wall-flexible diaphragm buildings," Journal of Structural Engineering, vol. 142, no. 2, article 04015137, 2016.

[5] M. Koliou, A. Filiatrault, D. J. Kelly, and J. Lawson, "Buildings with rigid walls and flexible roof diaphragms. II: evaluation of a new seismic design approach based on distributed diaphragm yielding," Journal of Structural Engineering, vol. 142, no. 3, article 04015167, 2016.

[6] Y. Yamazaki and H. Sakata, "Simplified modeling method and seismic force evaluation of building structures involving stiff cores," Journal of Structural and Construction Engineering (Transactions of AIJ), vol. 81, no. 720, pp. 291-301, 2016.

[7] C. Goertz, F. Mollaioli, and S. Tesfamariam, "Energy based seismic design of a timber core-wall multi-storey hybrid building," in Proceedings of 16th World Conference on Earthquake Engineering, Santiago, Chile, January 2017.

[8] H. Isoda and S. Tesfamariam, "Connections for timberconcrete hybrid building: experimental and numerical model results," Journal of Performance of Constructed Facilities, vol. 30, no. 5, article 04016024, 2016.

[9] H. Isoda, N. Kawai, M. Koshihara, Y. Araki, and S. Tesfamariam, "Timber-reinforced concrete core hybrid system: shake table experimental test," Journal of Structural Engineering, vol. 143, no. 1, article 04016152, 2017.

[10] D. Wu, Y. Yamazaki, S. Sawada, and H. Sakata, "Shaking table tests on 1/3-scale model of wooden horizontal hybrid 
structure," Journal of Structural Engineering, vol. 144, no. 8, article 04018123, 2018.

[11] American Society of Civil Engineers (ASCE), ASCE/SEI-7-10 Minimum Design Loads for Buildings, ASCE, Reston, VA, USA, 2010.

[12] Comité Européen de Normalisation (CEN), Eurocode 8, Design of Structures for Earthquake Resistance-Part 1: General Rules, Seismic Actions, and Rules for Buildings, CEN, Brussels, Belgium, 2004.

[13] International Conference of Building Officials (ICBO), Uniform Building Code, Whittier, ICBO, Lansing, MI, USA, 1997.

[14] Ministry of Construction, Code for Seismic Design of Buildings, GB 50011-2010, China Architecture and Building Press, Beijing, China, 2010.

[15] D. Wu, Y. Yamazaki, S. Sawada, and H. Sakata, "Shaking table test on one third scaled model of wooden horizontal hybrid structure (part 6): parameter analysis," Summaries of Technical Papers of AIJ Annual Meeting, vol. C-1, pp. 39-40, 2018.

[16] Build Research Institute (BRI), The Technical Guidance for The Build of Design Earthquake Input, Building Center of Japan, Tokyo, Japan, 1992.

[17] A. K. Chopra, Dynamics of Structures, Theory and Applications to Earthquake Engineering, Prentice-Hall, Englewood Cliffs, NJ, USA, 1995. 


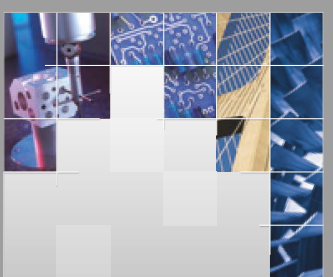

\section{Enfincering}
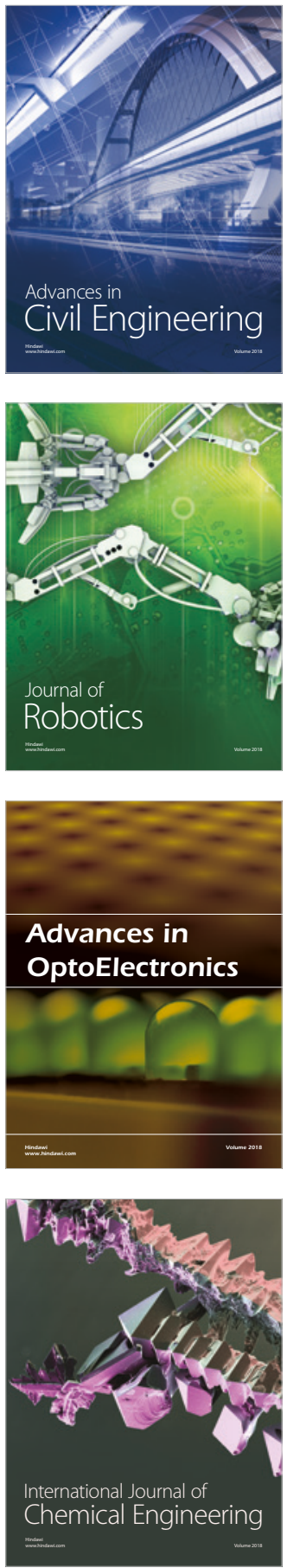

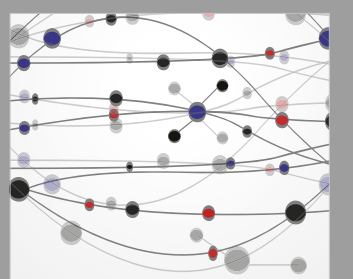

\section{Rotating \\ Machinery}

The Scientific World Journal

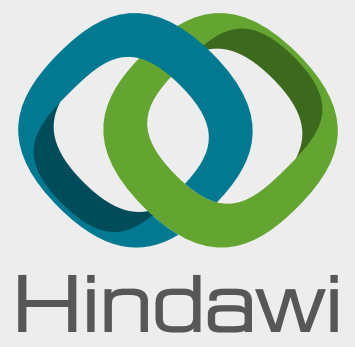

Submit your manuscripts at

www.hindawi.com
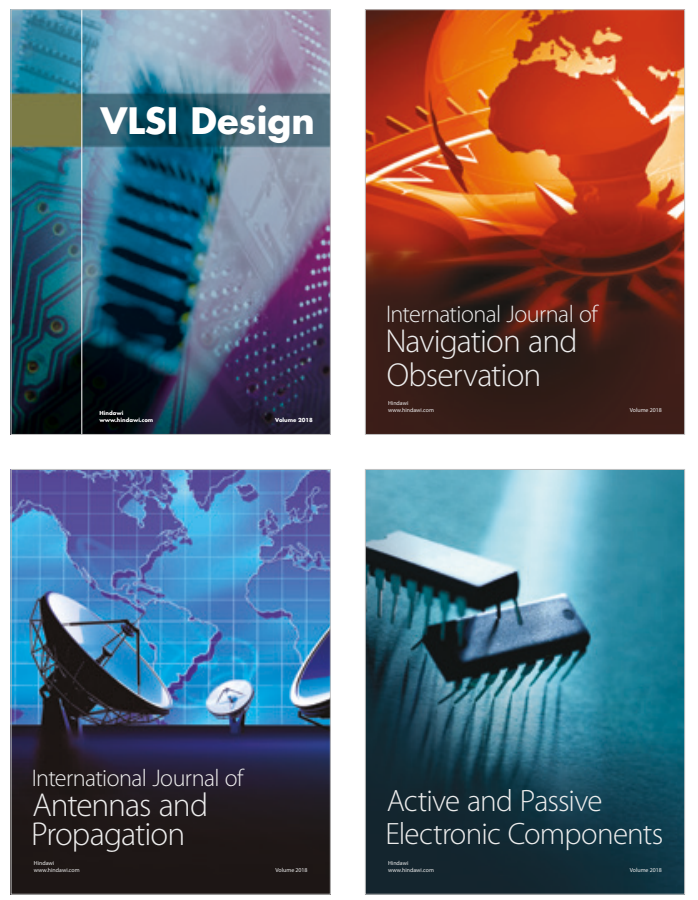
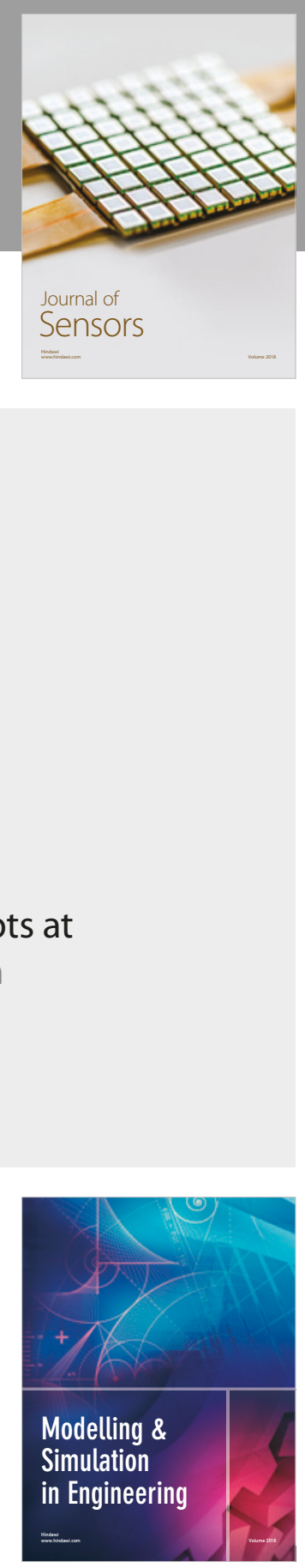

\section{Advances \\ Multimedia}
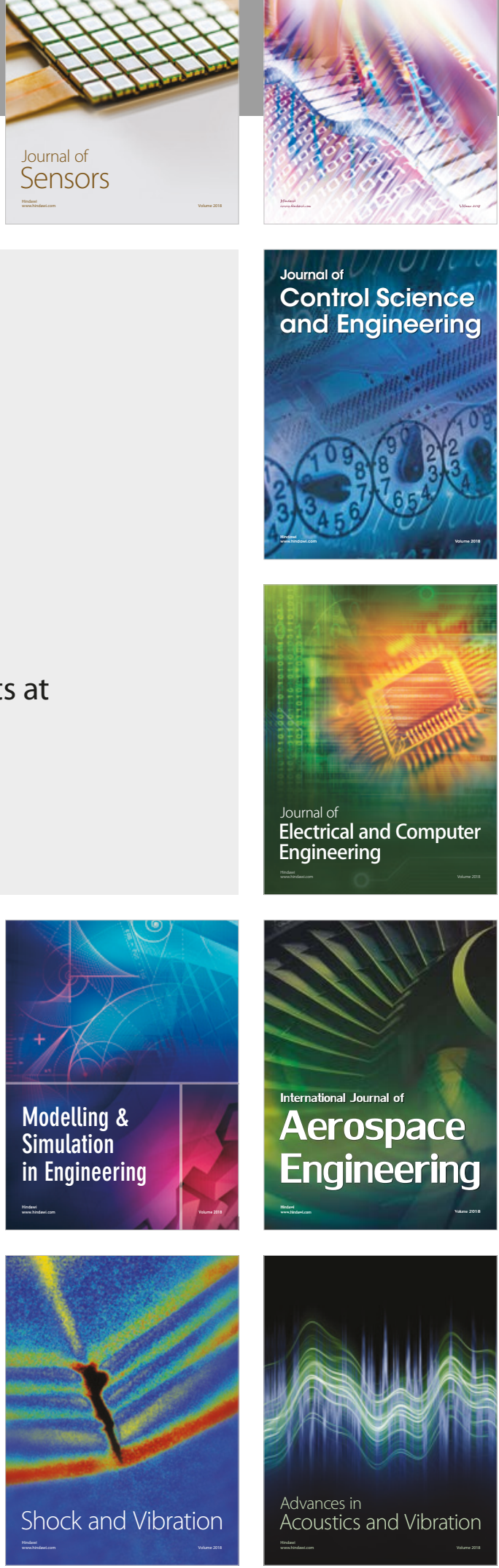